Journal of

Neurophysiology and Neurological Disorders

Research

\title{
Shigeru Tsuji (1936-2008): A Master in the Histochemistry of the Cholinergic Synapse - Insight for Future Researches
}

\section{Philippe Anglade $^{1^{*}}$ and Yamina Larabi-Godinot ${ }^{2}$}

128 bis Allée Piketty, Saint-Fargeau-Ponthierry, 77310 Saint-Fargeau-Ponthierry, France

${ }^{2} 44$, rue de Montmorency, 75003 Paris, France

${ }^{*}$ Corresponding author: Philippe Anglade, 28 bis Allée Piketty, Saint-Fargeau-Ponthierry, 77310 Saint-Fargeau-Ponthierry, France; Tel: 33-1-01 606575 15; E-mail: philippe-anglade@orange.fr

Received Date: May 02, 2019 Accepted Date: June 11, 2019 Published Date: June 13, 2019

Citation: Philippe Anglade, Yamina Larabi-Godinot (2019) Shigeru Tsuji (1936-2008): A Master in the Histochemistry of the Cholinergic Synapse - Insight for Future Researches. J Neurophysiol Neurol Disord 5: 1-11.

\begin{abstract}
The present paper is a contribution to the memory of a scientist and, thereby, a report about an outstanding research achievement that may help future investigators in the field of cholinergic nerve transmission. Indeed, Shigeru Tsuji realized a basic analysis of the histochemical reactions used to detect acetylcholinesterase activity. Moreover, he remains, until now, a pioneer in the in situ localization of the quaternary ammonium compounds, such as choline and acetylcholine. Always open-minded, Tsuji remarkably understood, at the end of his life, the relevance of initiating research in the newly emerging field of quantal neurobiology. Here, his significant findings will be put together to emphasize that they provide both enlightening data and very useful tools for further works in the domain of the cholinergic synapse.
\end{abstract}

\section{The birth of a vocation}

Shigeru Tsuji was born in Japan a few years before the Second World War. The young boy was thrown early in the tragic atmosphere prevailing at that time. And, later, the adolescent will be troubled by the contradiction that he had felt, during his childhood, between the militarist propaganda and the reality of the war. It is probable that such puzzling questions marked his personality at the point he will always be unsatisfied not to be able to understand the things as clearly as he wished. Trying to understand is a prevailing trait for a scientist. However, the origin of a vocation remains always beyond any rational consideration. Thus, precursor events appeared in the life of Tsuji as decisive milestones that engaged him for all his life. He liked to report that, during a lesson of biology delivered at school, he was fascinated when

C 2019 The Authors. Published by the JScholar under the terms of the Creative Commons Attribution License http://creativecommons.org/licenses/ by/3.0/, which permits unrestricted use, provided the original author and source are credited. watching the beating heart of a frog. This experience seemed decisive in his wish to study biology and understand this mysterious life he observed at once. Tsuji entered, thus, Tokyo University of Education where he obtained his master degree in the faculty of science. Then, he received the opportunity to spend two years in Germany to work in the laboratory of Kurt Greven (Institute of animal physiology, Frankfurt am Main University). Thus, at the end of a memorable travel by sea from Yokohama to Marseille, he discovered Europe and began his scientific life in Frankfurt am Main. There, he evidenced new centers of automatism in the chain of the nerve conductor system of the frog heart[1,2]. After coming back to Japan, Tsuji became interested to study thoroughly the neuronal activity of these nerve centers regulated by acetylcholine neurotransmission. He heard about the work of two famous French histochemists, René Couteaux and Jacques Taxi, who had devised a successful method to accurately visualize in situ the activity of acetylcholinesterase (AChE), the enzyme that catalyzed acetylcholine degradation [3].Then, with the aid of his future 
wife, Thérèse, Tsuji began exchanges by mail, and, through the recommendation of DeniseAlbe-Fessard (Laboratory of nerve centers physiology, Faculty of Sciences, Paris) he was invited in Paris by Couteaux to apply AChE histochemistry on the peripheral nervous system. When he entered for the first time the Parisian laboratory of cytology, the young Japanese fellow did not know that he would become one of its members and would stay there until his retirement!

\section{To the school of the Parisian neurobiologists}

Despite the obstacle of language and the cultural chock, Tsuji rapidly showed a particular aptitude for understanding the mechanisms of histochemical reactions. It is, thus, not surprising that, with the recommendation of Couteaux, he got a position at the C.N.R.S., the National Center of Scientific Research. In a few years, the young Japanese scientist, endowed with a communicative enthusiasm, became respected by his French scientific colleagues. He had, then, the unique opportunity to collaborate with some of the leading neuroscientists working in France at that time. In these years, he continued his study of the cholinergic nerve transmission, the domain he would never leave afterward. He participated to the immunocytochemical localization of AChE and of the acetylcholine receptor in the laboratory of Jean-Pierre Changeux (Pasteur Institute, Paris) [4,5]. He gave his contribution to pioneering works on the molecular species of AChE in the laboratory of Jean Massoulié (Physical and Chemical Biology Institute, Paris) [6]. He worked on the putative role of intra-cellular AChE in the laboratory of Ladislas Tauc (Laboratory of Cellular and Molecular Biology, Gif-sur-Yvette) [7]. These years passed in a very stimulating atmosphere provided Tsuji with a strong formation for advanced research. Thus, his expertise in electron microscopy largely contributed to the basic study performed by Denise Cade (Pierre et Marie Curie University) on the in vitro de-differentiation of the proximal tubules of the bovine nephrons [8]. Tsuji was hence armed to begin his original contribution to the understanding of the cholinergic synapse. This started when he attempted to localize AChE on $35 \mathrm{~nm}$ thick ultra-thin frozen sections by a negatively stained immune complex. By this technical tour-de-force, he obtained an AChE immuno-staining on the basal lamina of the synaptic cleft in the electric organ of electric eel [9].
The cellular localization of the cholinergic agents: a rather hard challenge for histochemists.

Degradation of acetylcholine released from nerve terminals was considered as an essential step for the fine regulation of the action of the neurotransmitter on the target cells. Thus, thorough researches were undertaken to localize and identify AChE, the agent of acetylcholine degradation [for review see 10]. In situ localization of AChE activity became possible thanks to the Koelle and Friedenwald's method [11] that used acetylthiocholine as an artificial substrate of AChE. Thiocholine was formed as the reaction product and precipitated at the enzymatic site with copper ions. Thus the final precipitates of cupro-thiocholine (converted in cupric sulphide, a black precipitate) revealed in situ the sites of AChE activity, providing controls of the specificity for AChE. After its subsequent improvement to decrease the artifactual diffusion of the precipitates [3], AChE histochemistry became an important tool for the in situ study of the cholinergic nervous system. A method, based on the formation of the metallic precipitate of cupric ferrocyanide at the site of AChE activity, was proposed by Karnovsky and Roots [12]. The reaction of Karnovsky and Roots allowed reliable observation of enzymatic activity at the ultra-structural level, and, thus, gave a new impulse in the histochemistry of the cholinergic nervous system. It was shown that AChE activity was located in the synaptic cleft associated with cholinergic neurons $[13,14]$. This was confirmed when AChE itself was localized by immuno-cytologic procedures using specific antibodies directed against the purified enzyme [15]. However, AChE activity was currently detected not only in the cholinergic but also in the non-cholinergic neuronal cell bodies. Since histochemical detection of AChE was not suitable to identify unequivocally the cell bodies of the cholinergic neurons, it was considered as a last resource, only useful for general staining of nerve circuits. Moreover, in situ detection of choline acetyltransferase (ChAT), the synthesis enzyme of acetylcholine, and of its enzymatic activity, remained a puzzling question, especially in the peripheral nervous system. At last, despite the breakthrough made in the research on acetylcholine receptors [16], the study of cholinergic synapse in situ was hampered by the impossibility to precipitate acetylcholine itself for a suitable localization [see 17]. All these obstacles were certainly much more than sufficient to engage an eager histochemist, as was Tsuji, to gather his strengths for the scientific challenge of the cholinergic synapse! (Figure.1) 


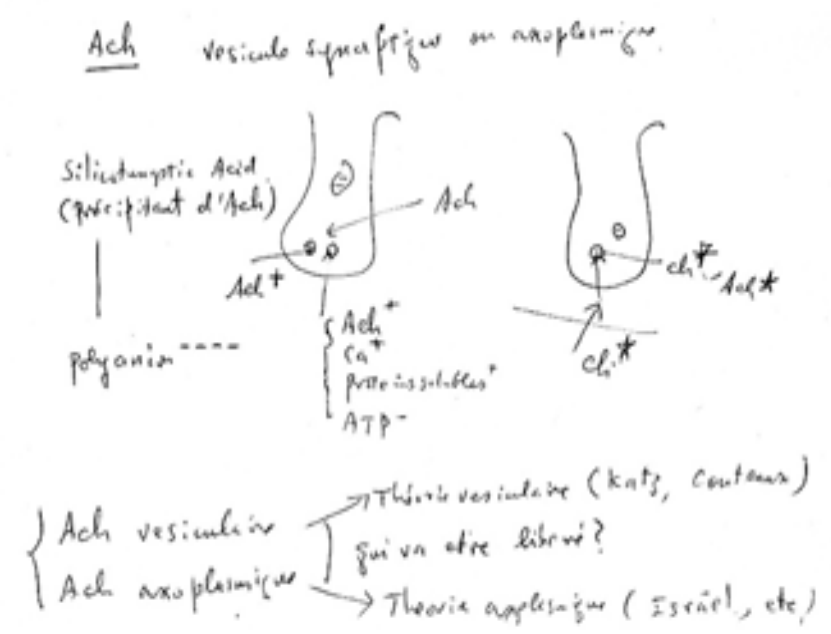

Figure. 1: Draft written in French by Tsuji on the two main theories of acetylcholine (Ach) release in the cholinergic synapse. Acetylcholine is released in the synaptic cleft from exocytosis of synaptic vesicles (vesicular theory, favoured by B. Katz and R. Couteaux) or through axoplasmic diffusion (non-vesicular or axoplasmic theory, favoured by M. Israël). Still today, the mechanism of acetylcholine release remains to be clearly elucidated.

\section{Histochemical detection of AChE activity: when old methods shed light on new problems}

Thanks to their modification of the original Koelle and Friedenwald's method, Couteaux and Taxi obtained a satisfactory localization of AChE activity in the frog neuromuscular junction [3]. When these authors observed, at light microscope level, AChE activity underlying the folds of the sarcolemma outside of the nerve endings, they proved the relevance of histochemistry for the investigation of the nervous system. This all the more as Karnovsky and Roots devised, a decade later, a method enabling suitable localization of AChE activity under electron microscope [12]. Tsuji began his active research in cholinergic nerve system in this hinge period. He rapidly understood that the sharpness of the localization of AChE activity could still be improved by obtaining a minimal diffusion of the histochemical precipitates. He, thus, began thorough methodological research that will last on more than 30 years, with ups and downs before obtaining a fine result at the end.

Following a trend of his personality, Tsuji looked at first for elucidating the components formed in the "soups" of the histochemical reactions. He liked to compare maliciously histochemistry with good cooking and a beautiful painting.
This humor masked a profound exigence towards experimental results. Furthermore, Tsuji always thought that science without joy and beauty is not more than a poor and sad thing (Figure.2)
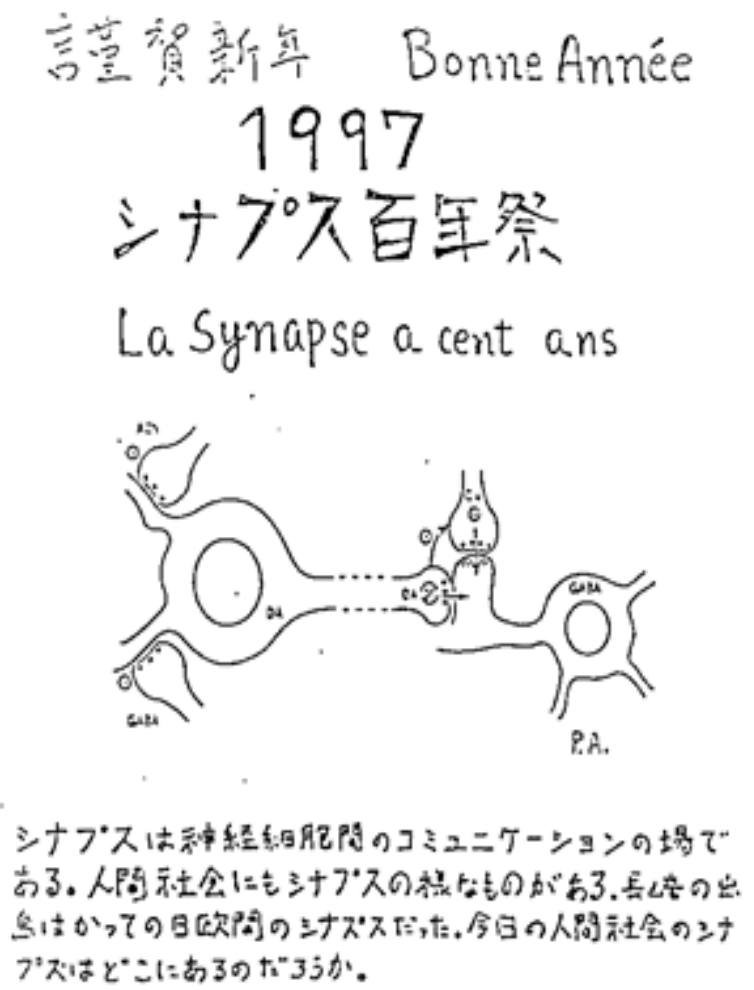

Li synapse est un lieu de comaturicotion erthe lex. celiules nexveuses. Dans les actietes humaines, it y a gutyee chose de sembrable à Aa synopse. Adraefois à Nagasaki, t'ile de Deshima itait une vrale synapse onithe Europe et Japar. O: thouverons-nous, aujousd'tui, lis 'sgnapses" dass ses socitid?

Figure. 2: Postcard made by Tsuji on the occasion of the 1997 New Year. The year 1997 marked the centenary of the introduction of the concept of the synapse by CS Sherrington (see 10). In the following text, originally written in Japanese and in French, Tsuji compared the synapses to inter-relation places in human societies:"The synapse is a place of communication between nerve cells. In human societies, something is similar to synapse. In the past in Nagasaki, Deshima island was a true synapse between Europa and Japan. Where could we find, today, synapses in our societies?" (from "Le Cerveau au Microscope". (2017). Barbara J-G and Clarac Feds., Hermann, Paris.

Thus, Tsuji undertook a sharp analysis of the histochemical reactions devised by Koelle and Friedenwald and by Karnovsky and Roots for localizing AChE activity. His work brought out basic data that remain until today a reference in this domain. Indeed, he demonstrated that the reaction of Koelle and Friedenwald did not occur when iodide was replaced by another halogen anion, such as chloride, and that the histochemical pre- 
cipitate actually was cuprous thiocholine iodide [18]. The chemical analysis of the medium of Karnovsky and Roots showed the unexpected presence of the precipitate taking place in Koelle and Friedenwald's reaction, in addition to cupric ferrocyanide $\left(\mathrm{Cu}^{++}{ }_{2} \mathrm{Fe}^{++}(\mathrm{CN})_{6}\right)$, the well-known precipitate of Karnovsky and Roots. It was demonstrated that, in the medium of Karnovsky and Roots, cuprous thiocholine iodide reacted with $\mathrm{Fe}^{+++}(\mathrm{CN})_{6}$ to form $\mathrm{Cu}_{3}^{+} \mathrm{Fe}^{+++}(\mathrm{CN})_{6}$. Thus, the reaction of Karnovsky and Roots actually resulted in the formation of two precipitates, $\mathrm{Cu}^{++}{ }_{2} \mathrm{Fe}^{++}$ $(\mathrm{CN})_{6}$ and $\mathrm{Cu}_{3}^{+} \mathrm{Fe}^{+++}(\mathrm{CN})_{6}(26)$. Moreover, these two products may be transformed into each other by alternating intra-molecular oxide-reduction [19]. However, these significant in vitro data did not practically result in a decisive decrease of the diffusion artifacts of the precipitates in the in situ localization of AChE activity. A solution was unexpectedly brought by the birth country of Tsuji when Hisao Tago and his collaborators devised a new method based on diamino-benzidine oxidation by the metallic precipitates formed in the reaction of Karnovsky and Roots [20]. The method of Tago enabled both sharp and intense histochemical staining of AChE activity and became commonly used in a series of modified forms. Then, inspired by these new results, Tsuji undertook a methodological analysis of the different catalytic activities of the Karnovsky and Roots precipitate and obtained, in the end, the images that he was looking for from the beginning [21] (Figures.3 and 4).The localization of AChE activity became reliable at the scale of an organelle or of an intracellular compartment. It is noteworthy that, already before this last work, the outstanding contribution of Tsuji in AChE histochemistry was remarkably resumed by Peter. J.S toward in a textbook of histochemistry [22].

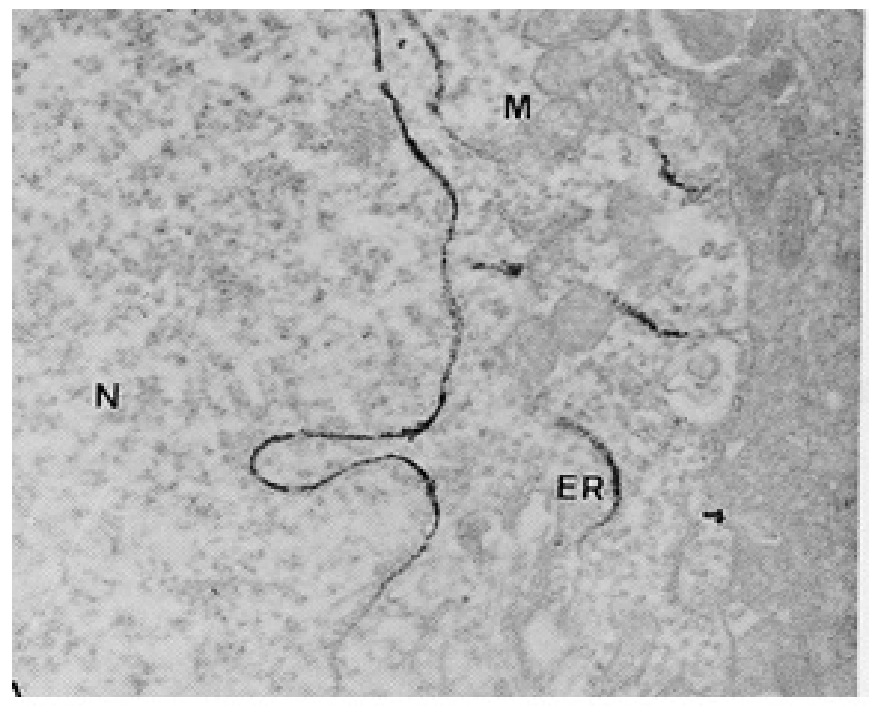

Figure. 3: AChE activity in a dopaminergic neuron of the rat substantia nigra detected by Tago's method without metallic impregnation, and observed at electron microscopic level: The dark precipitates of $\mathrm{DAB}$ oxidized by cupric ferrocyanide are finely localized in the endoplasmic reticulum (ER) and in the nuclear envelop. M: mitochondria, N: nucleus. (x 24,000). (From Tsuji, 1998)

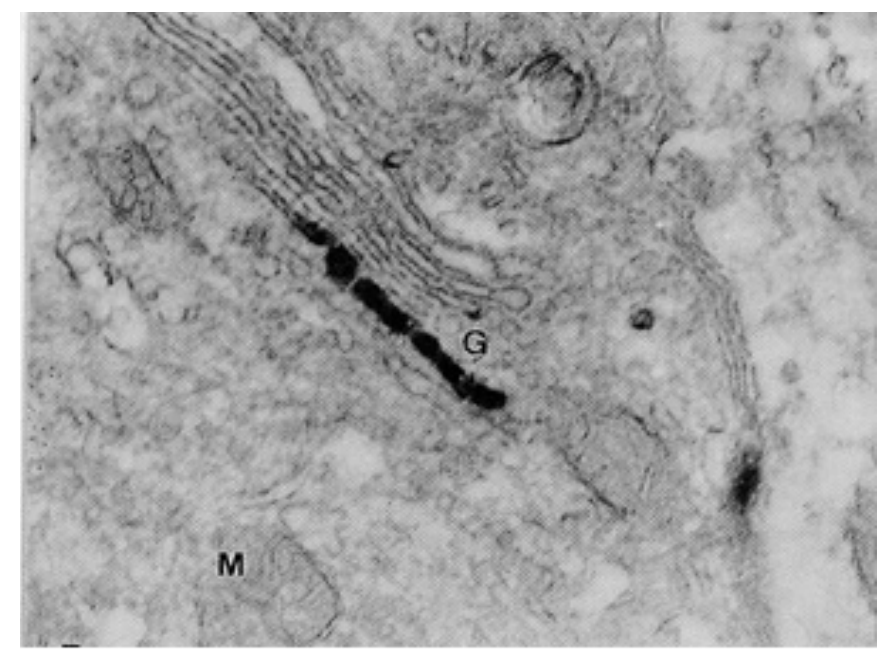

Figure. 4: Cytoplasm of a dopaminergic neuron at electron microscopic level. AChE activity detected by Tago's method without metallic impregnation is visible as dark precipitates in the cisternae of the Golgi apparatus (G). M: mitochondria. (x 84,000). (From Tsuji, 1998)

The aptitude of Tsuji for re-using and renewing the neglected methods was particularly well illustrated in the field of AChE histochemistry. Indeed, he used the precipitation of organic non-metallic compounds, such as red a-naphtyl azo dye [23], to reveal AChE activity after silver nitrate impregnation [24]. Moreover, employing these non-metallic compounds for the histochemical reaction, he devised a method combining the localization of AChE activity and neuropeptide immunoreactivity [25].

This story is not only a series of interesting results for the records of histochemistry. Indeed, the localization of AChE activity recovered primal significance when were established the non-cholinergic functions of cholinesterases in basic phenomena, such as cell-cell interaction, cell division, cell differentiation and neural development [see 26]. Several investigations confirmed this new field of research, such as evidence for a morphogenetic role of AChE in axonal outgrowth [27]or induction of AChE during apoptosis [28].Tsuji participated with enthusiasm for this renewal. Thus, in collaboration with morphologists working on the central nervous system, he provided ultra-structural data suggesting AChE release from the dendrites of the dopaminergic neurons in the rat substantia nigra [29]. Moreover, using immunocytochemistry, Tsuji detected AChE in structures 
identified as dendritic spinules. These data suggested a putative role of AChE in synaptic plasticity, in particular in the remodeling of the cholinergic synapses [30].

The discovery of the role of AChE in the pathogenesis of Alzheimer's disease could be of therapeutic importance. Until now, Alzheimer's disease is most commonly treated by AChE inhibitors in order to reduce the symptoms due to the loss of cholinergic neurons. However, AChE might intervene in the pathological process by favoring the aggregation of beta-amyloid peptide and modulating tau-phosphorylation [31-33]. Therefore, the proposition of new AChE inhibitors specifically targeting beta-amyloid deposition and abnormal tau-phosphorylation may lead to an improvement in the cure of Alzheimer's disease [31-33]. In this context, Tsuji showed, thanks to the fruitful support of Tsutomu Hashikawa (laboratory of Neural architecture, RIKEN, Brain Science Institute, Wako, Japan), that the use of new methods, such as backscattered electron imaging and X-ray mapping, enabled the observation of extra-neuronal AChE activity in fine neural networks [34].

Finally, the important contribution of Tsuji in AChE histochemistry could provide useful tools to understand so far unknown properties of this enzyme.

\section{Ionic fixation of acetylcholine-like cations: sun and rain on original research}

This is now a key point of Tsuji's work. It is the best and the most disputable part of his research. The first wish of this report is that the best be highly considered for future investigations, whereas most disputable be simply seen as the reverse of the medal.

Tsuji wrote in a first paper: "A chromatography technique which characterizes choline by phosphomolybdic acid (...) an analogous molybdenum compound of PTA (phosphotungstic acid), gave us the idea of using an heteropoly tungstic acid for cytochemistry of diffusible substances in nerve terminals." [35]. Thus, he understood that tungstic heteropolyanions might precipitate acetylcholine in situ, providing the use of suitable experimental conditions. And, indeed, after using phosphomolybdic or silicotungstic acid (STA) at low $\mathrm{pH}$, he regularly observed point-like precipitates in the synaptic vesicles of the cholinergic nerve terminals of the frog neuromuscular junction, whereas only background staining was seen in the cells of muscular and connective tissue [36-37] (Figure. 5).Tsuji interpreted the point-like staining as vesicular acetylcholine precipitated in situ by STA. He called this method "ionic fixation" since STA has the property to precipitate quaternary ammoniums, such as choline or acetylcholine, after ionic interaction.

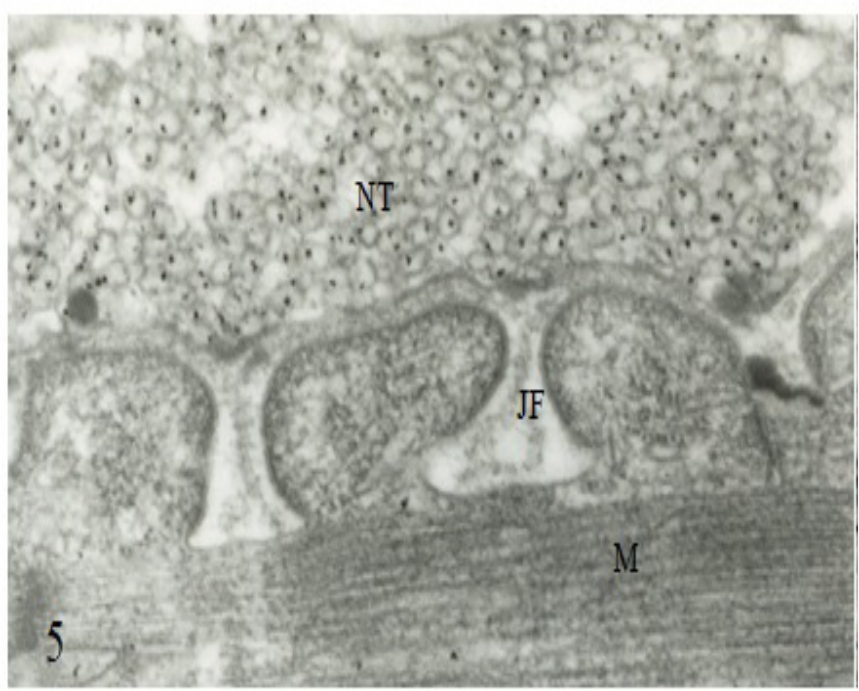

Figure. 5: Ultrastructural localization of acetylcholine-like cations in a frog neuromuscular junction at $25^{\circ} \mathrm{C}$ (resting state). Point-like precipitates of acetylcholine-like cations are observed in the synaptic vesicles of the nerve terminal (NT). JF: a junctional fold of the synaptic cleft, M: muscle cell.(x 100,000)

This result appeared, at first, as a breakthrough in the wall stood up by the impossibility to localize acetylcholine in situ. However, STA and the other hetero-polyanions could precipitate, not only choline and acetylcholine but also, at variable degrees, all the quaternary ammonium compounds including those of soluble proteins. Therefore, the method was finally named "ionic-fixation of acetylcholine-like cations". Thus, the specificity of this method for in situ localization remained to be established. And, Tsuji will accept to take up this challenge in the following years.

Nevertheless, the sun rose when ionic fixation was applied at low temperature in resting and excited frog neuromuscular junction. Indeed, the diffusion of acetylcholine-like cations in the synaptic cleft was markedly reduced at temperatures ranging from 0 to 4 $\mathrm{C}^{\circ}$. Tsuji obtained, in these conditions, spot-like precipitates in the synaptic space just at the level of the active zone described by Couteaux and Pécot-Dechavassine [38,39] (Figure. 6). These images displayed twin spots at the supposed sites of the double rows of exocytotic vesicles, and laminar precipitates extending in the folds of the subneural apparatus [40]. They were heartfully received by Couteaux who recognized the best confirmation of his hypothesis of "active zone" of the nerve terminals. Indeed, when it was applied at low temperature or during nerve stimulation, ionic fixation evidenced that in the neuromuscular junction an intense activity was related to the structures of the active zone. 
This work is certainly one of the most beautiful contributions of Tsuji.

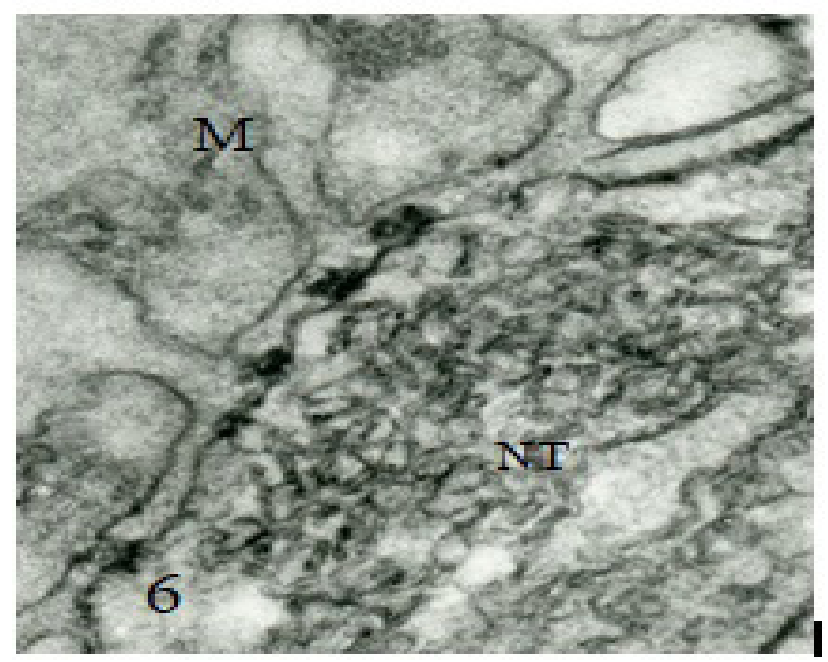

Figure. 6: Ultrastructural localization of acetylcholine-like cations in frog neuromuscular junction at $0^{\circ} \mathrm{C}$. The diffusion of acetylcholine-like cations in the synaptic cleft is reduced at low temperature, which enables the visualization of pairs of diffuse precipitates beneath the sites of the active zone of the nerve terminal (NT). M: muscle cell. (x 100,000)

Clouds came rapidly after in the shape of scepticism concerning the specificity of the ionic fixation for acetylcholine. Tsuji was probably not sufficiently cautious about the confusion he might cause when he displayed his results obtained in a series of different experimental conditions. The stringent treatments of the cellular tissues (low temperature, nerve stimulation, low $\mathrm{pH}$ of ionic fixation) caused poor preservation of the ultra-structures and some of the precipitates were rather questionable. A rain of critics pushed Tsuji to undertake a study to gauge the specificity of the ionic fixation for acetylcholine. He asked the assistance of Tadakazu Ohoka who was not only his friend but also a bright biochemist. In vitro, experimental models and ultrastructural observation of cholinergic and non-cholinergic nerve terminals in the frog heart enabled to partly answer to the criticisms. The results suggested a relative specificity of ionic fixation by STA for acetylcholine compared to the other neurotransmitters[41]. In fact, in the range of the concentrations found in the cellular tissues, only acetylcholine, choline, and to a lesser extent, serotonin can be precipitated by STA. Moreover, electron microscopic studies revealed punctiform precipitates in small clear vesicles of presumed cholinergic terminals, whereas they were not found in the large dense-cored vesicles of the presumed noradrenergic varicosities. However, soluble proteins were precipitated at low concentrations by STA. This remained a question, although the pattern of point-like staining in the synaptic vesicles corresponded to the distribution of the cholinergic vesicles.
Further works allowed to precise both the limits and the relevance of ionic fixation for specific detection of cholinergic nerve terminals. By using this method, the plasticity of the nerve afferents to nigrostriatal dopaminergic neurons was evidenced in Parkinson's disease, although the cholinergic nature of all the stained terminals could not be assessed [42] (Figure. 7). Moreover, ionic fixation seemed more specific for acetylcholine in the peripheral nerve system $[37,41]$ than in the brain where the concentrations of neurotransmitters are the highest. Since, until now, ionic fixation by STA is the unique method allowing in situ precipitation of acetylcholine, further works must be performed in order to unequivocally characterize the compounds of the precipitates observed under an electron microscope.

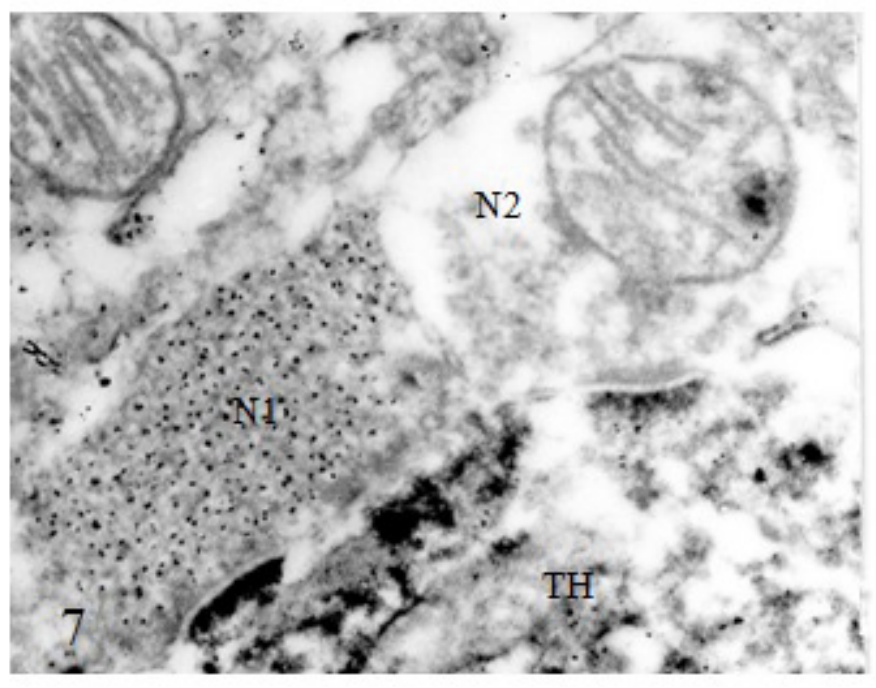

Figure. 7: Ionic fixation of acetylcholine-like cations after tyrosine hydroxylase (TH) immunostaining in the substantia nigra of post-mortem human brain. Two nerve endings (N1 and N2) are observed in synaptic contact with a TH-immunoreactive dendritic process of a dopaminergic neuron $(\mathrm{TH})$ stained by dark $\mathrm{DAB}$ precipitates. Point-like precipitates of acetylcholine-like cations are present in the synaptic vesicles of $\mathrm{N} 1$ and absent in the synaptic vesicles of N2.(x 60,000)

Curiously, the soundness of this method for future researches came from its successful application to choline autoradiography. Indeed, STA enables to limit the diffusion of $\left[{ }^{3} \mathrm{H}\right]$ choline captured by cholinergic neurons and allows an intense and reliable autoradiographic labeling of cholinergic pathways [43]. This is all the more interesting as ionic fixation is compatible with immuno-cytochemical reaction [43].In the same way, an important capture of $\left[{ }^{3} \mathrm{H}\right]$ choline was evidenced in fibrocytes surrounding the frog motor end-plates [44] (Figure. 8). The contribution of Silvia Araneda, a cytochemistry coming from Chili, and of Ion Motelica-Heino, a physiologist born in Moldavia, was essential for obtaining these crucial results. These colleagues of 
Tsuji proved on this occasion that science may, fortunately, gather human beings for the best...

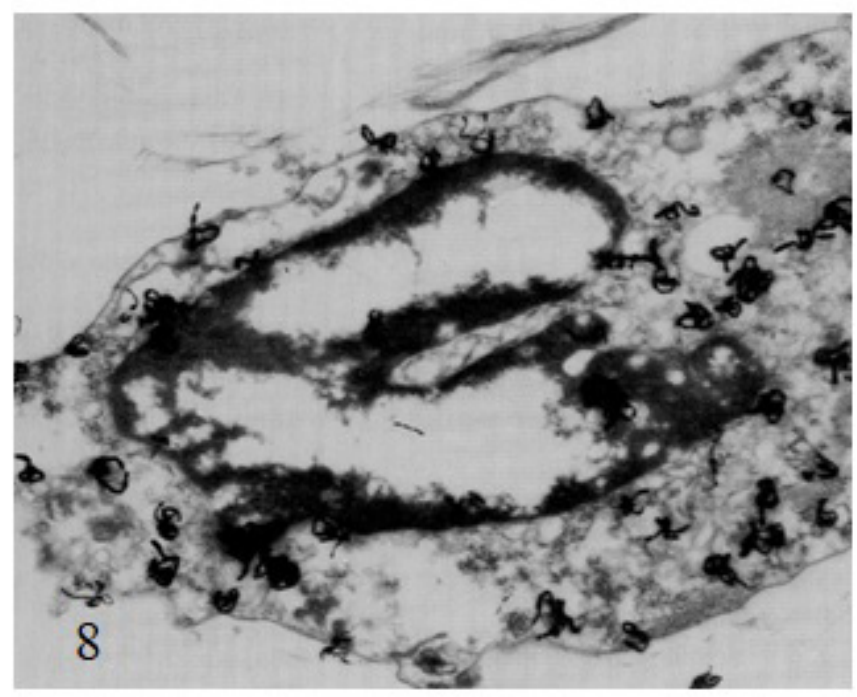

Figure. 8: Ionic fixation applied to the frog neuromuscular junction after loading with $\left[{ }^{3} \mathrm{H}\right]$ choline and brief tetanic stimulation. The cytoplasm of a fibrocyte situated in the vicinity of the neuromuscular junction is intensely labeled with silver grains whereas the nucleus is almost devoid of the autoradiographic label. ( $\mathrm{x}$ 20,000), (reproduced from the figures of ref. 44).

In one word, ionic fixation is a major contribution for a reliable visualization of quaternary ammonium compounds used as histochemical markers, such as $\left[{ }^{3} \mathrm{H}\right]$ choline and d-tubocurarine [45]. Its relative specificity for acetylcholine in situ remains a question to be precisely estimated. This method must be a sound and useful tool for future studies in the domain of the cholinergic synapse. This is certainly the best wish that Tsuji would transmit to the next generation of researchers.

\section{When research and friendship gathered...}

The ways of scientific research are often going by human friendship. Thus, Tsuji met Shomatsu Yokoyama in the laboratory of Greven, at the time when he was a young physiologist who was studying the nerve conductor system of the frog heart. In these years, Yokoyama was already an experimented scientist, at the head of the department of physiology of the Medical College of Fukushima, a middle-town in the north of Japan. His humane and courageous attitude during the tragic years of the Second World War and his sound personality marked Tsuji a lot. And from the first meeting until the death of the old master of Fukushima that would occur 30 years later, an exceptional friendship linked them with each other. Tsuji reported himself this story in the obituary he wrote after the decease of Yokoyama [46]. Indeed, the Professor of Fukushima was a pioneer in the electrophysiology of the enteric nervous system. After his retirement, he spent, in 1981, one year in Paris and, there, initiated Tsuji in the physiology of the intestinal nerve plexuses [47]. Following this collaboration, Yokoyama invited Tsuji to work in this domain through the hospitality of Tsuyoshi Ozaki, a pupil of Yokoyama, an expert in electrophysiology. Then, from 1985, Tsuji began to work, during annual stays, in the National Institute for Physiological Sciences in Okazaki, a Japanese town situated near Nagoya. The greeting of the scientists of Okazaki's Institute was such that Tsuji received moral support at the time when, in France, it was raining on the "ionic fixation". Thanks to the exceptional scientific and human conditions gathered there by many outstanding researchers coming from all parts of Japan, Tsuji achieved an original contribution on the role of the myenteric plexus in the intestinal peristalsis [48].

During this period, Tsuji renewed with Japanese biologists, and, through travels and collaborations, became aware of their vitality. He, thus, received a substantial influence from Tsuneo Fujita (Department of Anatomy, Niigata University School of Medicine, Niigata) in the laboratory of whom he was used to go. In Niigata, a town situated on the coast of Japan Sea, Fujita animated a famous school of histologists working on nervous and endocrine systems, among them, Shigeru Kobayashi, Hisatake Kondo, and Toshihiko Iwanaga. Backed by the physiologist Tomio Kanno (Department of Physiology, Faculty of Veterinary Medicine, Hokkaido University, Sapporo), and by the biochemist Noboru Yanaihara (Laboratory of Bioorganic Chemistry, Shizuoka College of Pharmacy, Shizuoka), Fujita originated the concept following which endocrine and neuroendocrine cells could be considered as "paraneurons", close to neurons from a structural and functional point of view $[49,50]$. However, the paraneuron concept, reflecting eastern philosophy, was not well understood both in Europe and America, where scientists are used to thinking with well-defined categories.

Tsuji was also influenced by the histochemistry working in the laboratory of Toshihiro Maeda (Department of Anatomy, Shiga University of Medical Science) situated in Otsu, near Biwa lake. There, he benefited from the expertise of Hiroshi Kimura, when he evidenced an intriguing binding avidity of immunoglobulins $G$ for acetylcholine [17]. In this place, he also met Hisao Tago the author of the famous histochemical method for in situ detection of AChE activity. Later, Tago visited The National Institute for Physiological Sciences in Okazaki where Tsuji was used to working during his stays in Japan. On this occasion, the two scientists could manage free-time to talk with each other. During this meeting, Tago confessed with humor that his discov- 
ery was due to a mistake of tissues handling he made, one day, during histochemical staining.

Tsuji was endowed with a particular sense for elucidating the chemical interactions between ions or molecules in the cellular tissues. It is, thus, not surprising that he felt a great interest for the book written by Pascal Mentré on the practically unknown (but probably basic) role of cellular water in the intermolecular reactions [51]. He, himself, devoted huge energy to promote and achieve the Japanese translation of this original work thanks to the unconditional support and contribution of his Japanese scientific friends [51].

When the time of retirement came in 2002, Tsuji was ready for continuing his researches. He founded an unexpected "International Institute of Neuroscience", the seat of which was in this house of Bagneux, in the suburbs of Paris. On this occasion, the underground of his house was endowed with a suitable laboratory and an informative library. The functioning of this original institute was simple and sound: Tsuji made, during biannual stays, the experiences of physiology in the laboratory of Yoshifumi Katayama, his friend working in Tokyo Medical and Dental University. There, Keiji Hirai brought them his competence in electrophysiology. After coming back to Paris, he could treat the experimental preparations in his home-laboratory of Bagneux. Then, he observed tissues under the electron microscope of the Department of Cytology of Pierre et Marie Curie University, where he benefited from the expertise of Mrs. MarieJeanne Brisorgueil in electron microscopy. Moreover, Tsuji was guided in immunology by Gabriel Peltre, (Laboratory of « Allergies et from the environment " from "Ecole Supérieure de Physique et Chimie Industrielles » in Paris). And, in the end, a pool of readers and correctors was ready to bring the final touch to the manuscripts! The activity of this international research team was crowned by original publications on synaptic cobalt ultrastructural localization [52], detection of cholinergic synaptic transmission after staining of $\mathrm{Cu}^{++}$ions incorporated in the neuromuscular junction [53] and visualization of the cytomatrixrelated part of the nicotinic acetylcholine receptors [45].

In a personal letter written a few months before his death, Tsuji expressed his intent to work in the domain of "quantum biology", and search for putative electron transfers in the active zone of the synapse (personal communication). At that time, "quantum biology" remained an almost unexplored concept in neurobiology, and this term itself was rarely used by the neuroscientists. Nevertheless, with the aid of his colleagues of Gif-sur-Yvette, Jean-Pierre Denizot, and Jordi Molgo, Tsuji ob- served, in the neuromuscular junction, an increase of the nerve transmission induced by methylene blue reduction at the level of the presynaptic membrane. He interpreted his results as putative electron transfers from molecules of the presynaptic membrane to methylene blue situated in the synaptic cleft (personal communication). Stimulated by his clear-sighted emphasis on "quantum neurobiology", two of his pupils, Philippe Anglade and Yamina Larabi-Godinot, proposed that, in the living brain, receptor proteins could function as holographic media, integrating and recording electron or proton interferences. Their hypothesis was sustained by structural analogies between holographic photoreceptor proteins, such as rhodopsin, and neurotransmitter receptors. Thus, investigations with the aid of scanning tunneling microscopy, transient absorption spectroscopy or holographic imaging of atoms might bring new data on learning and memory in the living brain [54-56].

Once, Maurice Israël (Laboratory of cellular and molecular biology, CNRS, Gif-sur-Yvette) proposed a name for the laboratory that his friend had settled in his house of Bagneux: "Room René Couteaux". This is a summary of the scientific inspiration of Tsuji who was proud to be considered as a true pupil of Couteaux, the founder of the modern school of French neurocytology. The pupil paid homage to his master in the last publication [57], and in a symposium organized in 2007 in Paris by Jean-Gaël Barbara (REHSEIS Laboratory, CNRS UMR 7596) on the history of the French school of neuroanatomy [58]. In turn, Couteaux had, long before, confirmed that the work of Tsuji was a major contribution to neuroscience. Indeed, one day, using poetic humor towards his pupil, Couteaux told him: "As you know, the art of the Japanese painter Leonard Foujita ${ }^{a}$ is a foreign flower which bloomed on a foreign land”...

a Tsuguharu Fujita (also called Leonard Foujita) was born in 1886 in Tokyo. He was an expressionist Japanese painter who came and settled in France before the First World War. He left France in 1928 and, then, lived in different countries. A few years after the Second World War, he came back to France and took the French nationality in 1955. Foujita was baptized in the Catholic Church under the name of Leonard and deceased in Zurich in 1968.

Acknowledgments: We wish to thank Mrs. Thérèse Tsuji, Dr. Takeshi Shimahara, Pr. Maurice Israël, and Dr. Marc Godinot for their support and helpful reading of the manuscript.

N.B.: This text is a revised and enlarged version of a paper published in French: (Anglade P, Larabi-Godinot Y (2017). Shigeru 
Tsuji, maître d'œuvre dans l'histochimie de la synapse cholinergique. Le cerveau au microscope - La neuroanatomie française au XIX ${ }^{\mathrm{e}}$ et $\mathrm{XX}^{\mathrm{e}}$ siècles. Eds J.-G. Barbara, F. Clarac, Hermann, Paris, pp 333-356).

\section{References}

1) Tsuji S (1963) Das Action potential of the isolated bulbus cordis of the frog heart. natural sciences 50: 575.

2) Tsuji S (1964) Intracellular pacemaker potentials of the bulbus cordis of the Frog's heart. natural sciences 51: 141.

3) Couteaux R, Taxi J (1952) Histochemical research on distribution desactivités cholinestérasiques at the level of the myoneural synapse. Arch Anat Micr 41: 352-392.

4) Benda P, Tsuji S, Daussant J, Changeux JP (1970) Localization of acetylcholinesterase by immunofluorescence in eel electroplax. Nature 225: 1149-1150.

5) Bourgeois JP, Tsuji S, Boquet P, Pillot J, Ryter A and Changeux JP (1971) Localization of the cholinergic receptor protein by immunofluorescence in eel electroplax. FEBS Letters16: 92-94.

6) Tsuji S, Rieger F, Peltre G, Massoulie J, Benda P (1972) Acetylcholinesterase of the Muscle, Spinal Cord and Gymnote Brain. Demonstration of "native" molecular species and histochemical localization. J Neurochem 19 : 989-997.

7) Tauc L, Hoffmann A, Tsuji S, Hinzen DH, Faille L (1974) Transmission abolished on a cholinergic synapse after injection of acetylcholinesterase into the presynaptic neurone. Nature 250, 496-498.

8) Cade-Treyer D, Tsuji S (1975) In vitro culture of the proximal tubule of the bovine nephron. Cell Tiss Res163: 15-28.

9) Tsuji S (1981) Attempted direct visualization of negatively stained amplified immune complex of synaptic acetylcholinesterase using cryo ultramicrotomy sections. Histochemistry 72: 369-375.

10) Anglade P, Tsuji S (1997) The hundredth anniversary of the "synapse": I. A short history of the milestones in synapse research. Zool Sci14: 533-537.

11) Koelle GB, Friedenwald JS (1949) A histochemical method for localizing cholinesterase activity. Proc Soc Exp Biol Med 70: 617-622.

12) Karnovsky MJ, Roots L (1964) A “direct-coloring” thiocholine method for cholinesterases. J Histochem Cytochem 12: 219221.

13) McMahan UJ, Sanes, JR, Marshall LM (1978) Cholinesterase is associated with the basal lamina at the neuromuscular junction. Nature271: 172-174.
14) Tsuji S (1974) On the chemical basis of thiocholine methods for demonstration of acetylcholinesterase activities. Histochemistry 42: 99-110.

15) Tsuji S, Anglade $P$ (1997) The hundredth anniversary of the « synapse »: II. Study of the cholinergic synapse. Zool Sci14: 539548.

16) Changeux J-P (1990) The TiPs Lecture. The nicotinic acetylcholine receptor: an allosteric protein prototye of ligand-gated ion channels. Trends Pharmacol Sci11:485-492.

17) Tsuji S, Tooyama I, Kato T, Peltre G, Kimura H (2003) Binding avidity of immunoglobulin $\mathrm{G}$ for acetylcholine. Biomed Res 24: $217-221$.

18) Souchay P, Tsuji S (1970) Contribution to the study of the reaction of copper salts thiocholine used in the histochemical detection of cholinesterases. Ann Histochim15:263-271.

19) Tsuji S, Larabi Y (1983) A modification of the thiocholineferricyanide method of Karnovsky and Roots for localization of acetylcholinesterase activity without interference by Koelle's copper thiocholine iodide precipitate. Histochemistry 78:317323.

20) Tago H, Kimura H, Maeda T (1986) Visualization of detailed acetylcholinesterase fiber and neuron staining in rat brain by a sensitive histochemical procedure. J Histochem Cytochem34: 1431-1438.

21) Tsuji S (1998) Electron microscopic localization of acetylcholinesterase activity in the central nervous system: the chemical basis of catalytic activity of Hatchett's brown (cupric ferrocyanide)precipitate revealed by 3,3'-diaminobenzidine.Folia Histochem Cytobiol 36:67-70.

22) Stoward PJ, Pearse AGE (1991) Histochemistry Theoretical and Applied, Vol 3, Enzyme histochemistry, 4th ed., Churchill and Livingstone, Edinburgh.

23) Lehrer GM, Ornstein L (1959) A diazo coupling method for the electron microscopic localization of cholinesterase. J Bioph Biochem Cytol6: 399-406.

24) Tsuji S, Tobin-Gros C (1980) A simple silver nitrate impregnation of nerve fibers with preservation of acetylcholinesterase activity at the motor end-plate. Experientia 36: 1317-1319.

25) Anglade P, Michel C, Ozaki T, Tsuji S, Vignon X, et al. (1988) Simultaneous localization of acetylcholinesterase activity and met-enkephalin,, vasoactive intestinal peptide and substance P immuno reactivity in the rat my enteric plexus. Histochem J 20: 464-467.

26) Balasubramanian AS, Bhanumathy CD (1993) Noncholinergic functions of Cholinesterases. FASEB J7: 1354-1358. 
27) Bigbee JW, Sharma KV, Gupta JJ, Dupree JL (1999) A morphogenic role for acetylcholinesterase in axonal outgrowth during neural development. Environ. Health Persp. Suppl.-1 107: 81-87.

28) Zhang XJ, Yang L, Zhao Q, Caen JP, He HY, et al. (2002) Induction of acetylcholinesterase expression during apoptosis in various cell types. Cell death diff9:

$790-800$.

29) Anglade P, Grassi J, Motelica-Heino I, Hashikawa T, Tsuji S (1999) Ultrastructural evidence for dendritic release of acetylcholinesterase in the rat substantia nigra. Folia Histochem Cytobiol37: 243-247.

30) Ishii K, Hayashida T, Hashikawa T, Tsuji S (2004) Dendritic spinules in rat nigral neurons revealed by acetylcholinesterase immunocytochemistry and serial sections of the dendritic spine heads. Folia Histochem Cytobiol 42: 77-81.

31) Castro A, Martinez A (2006) Targeting beta-amyloid pathogenesis through acetylcholinesterase inhibitors. Curr Pharma Des12: 4377-4387.

32) Lane RM, Kivipelto M, Greig NH (2004) Acetylcholinesterase and its inhibition in Alzheimer disease. Clin Neuro Pharmacol 27: 141-149.

33) Silman I, Sussman JL (2005) Acetylcholinesterase: "classical" and "non-classical" functions and pharmacology. Curr Opin Pharmacol 5: 293-302

34) Tsuji S, Nakatomi R, Tsuchiya H, Hirai K, Katayama Y, et al. (2002) Perineuronal surface acetylcholinesterase activity of a fine neural network stained histochemically and observed with backscattered electron imaging and X-ray mapping methods. Brain Res Protocols9: 16-22.

35) Tsuji S, Alameddine HS (1981) Silicotungstic acid for cytochemical localization of water-soluble substance(s) of the cholinergic motor nerve terminal. Histochemistry73: 33-37.

36) Tsuji S, Alameddine HS, Nakanishi S, Ohoka T (1983) Molybdic and Tungstic heteropolyanions for "ionic fixation" of acetylcholine in cholinergic nerve terminals. Histochemistry77: 5156.

37) Tsuji S, Motelica-Heino I (1993) Further studies on electron microscopic localization of acetylcholine-like cations in frog neuromuscular junctions. Acta Histochem Cytochem26: 577582 .

38) Couteaux R, Pécot-Dechavassine M (1970) Synaptic vesicles and pouches level of "active areas" of the neuromuscular junction. C R Acad Sci Paris271 (Series D): 2346-2349.
39) Couteaux R, Pécot-Dechavassine M (1974) Specialized areas presynaptic membranes. C R Acad Sci Paris278 (Series D) : 291293.

40) Tsuji S (1985) Ultracytochemical localization of acetylcholine-like cations in excited motor end-plates by means of ionic fixation. Histochemistry 83: 213-219.

41) Ohoka T, Tsuji S (1988) The specificity of ionic fixation with silicotungstic acid for cytochemical localization and identification of acetylcholine in synaptic vesicles. Biomed Res 9: 335-341.

42) Anglade P, Tsuji S, Javoy-Agid F, Agid Y, Hirsch EC (1995) Plasticity of nerve afferents to nigrostriatal neurons in Parkinson's disease. Ann Neurol 37: 265-272.

43) Tsuji S, Motelica-Heino I, Brisorgueil M-J, Anglade P and Araneda S (1992) A Combined method of immunocytochemistry of choline-acetyltransferase detection and of autoradiography of $[3 \mathrm{H}]$ choline after retrograde axonal transport. Proc Japan Acad 68: 145-149.

44) Tsuji S, Motelica-Heino I, Anglade P (1997) The capture of $[3 \mathrm{H}]$ choline by fibrocytes of frog motor endplate region. Proc Japan Acad 73: 158-160.

45) Hirai K, Katayama Y, Peltre G, Tsuji S (2008) Ultrastructural visualization of the transmembranous and cytomatrix-related part of nicotinic acetylcholine receptor of frog motor endplate by means of an immunochemical avidity of IgG for d-tubocurarine. Folia Histochem Cytobiol 46: 111-116.

46) Tsuji S (1993) Obituary - Professor Syomatu Yokoyama. Founder of modern electrophysiology of the enteric nervous system. Acta Med Biol 41: 167-169.

47) Tsuji S, Yokoyama S (1982) Peristaltic reflex in the small intestine deprived of the mucosa. Jpn J Smooth Muscle Res18: 218220.

48) Tsuji S, Anglade P, Ozaki S, Sazi T, Yokoyama S (1992) Peristaltic movement evoked in an intestinal tube devoid of mucosa and submucosa. Jpn J Physiol 42: 363-375.

49) Fujita T, Kobayashi S (1979) Current views on the para neurone concept. Trends Neurosci 2: 27-30.

50) Fujita T, Kanno T, Yanaihara N, Miyoshi A (1983) Brain-gut axis. Biomed Res Found Tokyo.

51) Mentre P (1996) The water in the cell. A heterogeneous and dynamic interface of macromolecules. Masson, Paris. (Translated in Japanese under the title «Saibo no naka no mizu » by Tsuji S, Nakanishi S, Ochiai M, Ohoka T (2006),University of Tokyo Press).

52) Tanaka E, Ishii K, Akagi T, Hirai K, Motelica-Heino I, et al. 
(2004) A new cytochemical method for ultrastructural localization of $\mathrm{Co} 2+$ in rat hippocampal CA1 pyramidal neurons in vitro. J Neuro sci Method135:1-8.

53) Hirai K, Tanaka E, Motelica-Heino I, Katayama Y, Higashi H et al. (2006) A new cytochemical method for in situ detection of cholinergic synaptic transmission by staining of $\mathrm{Cu} 2+$ incorporated in frog neuromuscular junction during nerve stimulation. Biomed Res 27: 125-130.

54) Anglade P, Larabi-Godinot Y, Tsuji S (2014) Electron transfers and holographic molecules: why neuroscientists should take quantum phenomena into consideration. NeuroQuantology 12: 237-246.

55) Anglade P, Larabi-Godinot Y (2015) Do receptor proteins store holographic data in the brain? NeuroQuantology 13: 104107.

56) Anglade P, Larabi-Godinot Y (2018) Holographic processes involved in rhodopsin-mediated phototaxis? Neuroquantology 16: $172-174$

57) Tsuji S (2006) René Couteaux (1909-1999) and the morphological identification of synapes. Bio Cell 98: 503-509.

58) Tsuji S (2007) Morphological identification of the synapse in light microscopy and ultrastructural observation of presynaptic active zone by René Couteaux. In Symposium on the French neuroanatomy: from Louis Ranvier to René Couteaux, REHSEIS, Paris. 